Revista Brasileira de Agricultura Irrigada v.14, nº.1, p. 3854 - 3864, 2020

ISSN 1982-7679 (On-line)

Fortaleza, CE, INOVAGRI - http://www.inovagri.org.br

DOI: $10.7127 /$ rbai.v14n1001097

Protocolo 1097.20 - 18/06/2019 Aprovado em 11/05/2020

\title{
EMERGÊNCIA E CRESCIMENTO INICIAL EM PLÂNTULAS DE CULTIVARES DE FAVA IRRIGADA COM ÁGUAS SALINAS
}

Emanuel D’Araujo Ribeiro de Ceita ${ }^{1}$, Geocleber Gomes de Sousa Geocleber ${ }^{2}$, José Thomas Machado de Sousa ${ }^{3}$, Geovana Ferreira Goes ${ }^{3}$, Fred Denilson Barbosa da Silva ${ }^{4}$, Thales Vinicius de Araújo Viana ${ }^{5}$

\begin{abstract}
RESUMO
O excesso de sais afeta a germinação das sementes e crescimento inicial das plântulas. Objetivou-se com o presente trabalho avaliar a tolerância à salinidade de quatro cultivares de fava na emergência e no crescimento de plântulas. O experimento foi conduzido, em dezembro de 2017, na Horta Didática Professor Luiz Antônio da Silva, pertencente à Universidade da Integração Internacional da Lusofonia Afro-Brasileira (UNILAB), localizada no município de Redenção, Ceará. O delineamento experimental foi inteiramente casualizado (DIC), com quatro repetições de 25 sementes por unidade experimental, em esquema fatorial $5 \times 4$, referentes aos valores de condutividade elétrica da água de irrigação - CEa: 1,0;2,0; 3,0; 4,0 e 5,0 dS m${ }^{-1}$ versus quatro cultivares de fava (Branquinha - C1, Manteiguinha - C2, Espírito Santo - C3 e Orelha-de-Vó - C4). Aos 21 dias após a semeadura (DAS), foram avaliadas as seguintes variáveis: porcentagem de emergência, índice de velocidade de emergência, tempo médio de emergência, altura de plântula, diâmetro de caule, comprimento da raiz, massa seca da parte aérea, massa seca da raiz e massa seca total. A cultivar Orelha-de-Vó apresenta maior tolerância ao estresse salino na porcentagem de emergência, tempo médio de emergência, diâmetro de caule, comprimento da raiz, massa seca da raiz e massa seca total em relação às demais cultivares.
\end{abstract}

Palavras-chave: Phaseolus lunatus L., salinidade, tolerância

\section{EMERGENCE AND INITIAL GROWTH IN SEEDLINGS OF BEAN CULTIVARS IRRIGATED WITH SALINE WATER}

\footnotetext{
ABSTRACT

${ }^{1}$ Mestrando em Agronomia/UNESP

${ }^{2}$ Prof. Dr., Bolsista de Produtividade da FUNCAP, Instituto de Desenvolvimento Rural, Universidade da Integração Internacional da Lusofonia Afro-Brasileira, Redenção (UNILAB), CE, Brasil, e-mail: sousagg@ unilab.edu.br

${ }^{3}$ Graduandos em Agronomia, Instituto de Desenvolvimento Rural, Universidade da Integração Internacional da Lusofonia Afro-

Brasileira, Redenção, CE, Brasil, e-mail: thssousa2015@gmail.com; ggoes64@gmail.com

${ }^{4}$ Professor Dr., UNILAB, Redenção, CE, Brasil, e-mail: freddenilson@unilab.edu.br

${ }^{5}$ Professor Dr.,Universidade Federal do Ceará, Fortaleza, CE, Brasil, e-mail:thales@ufc.br
} 
The objective of this study was to evaluate the tolerance to salinity of four cultivars of beans in the emergency and seedling growth. The experiment was conducted in December 2017, in the Horta Didatica Professor Luiz Antônio da Silva, belonging to the Unilab, located in the municipality of Redenção, Ceará. The experimental design was completely randomized (CRD), with four replications of 25 seeds per experimental unit, in $5 \times 4$ factorial scheme, referring to the values of electrical conductivity of irrigation water - Ecw: $1.0 ; 2.0 ; 3.0 ; 4.0$ and $5.0 \mathrm{dS} \mathrm{m}^{-1}$, versus four bean cultivars (Branquinha - C1, Manteiguinha - C2, Espírito Santo - C3 and Orelha-de-Vó - C4). At 21 days after sowing (DAS), the following variables were evaluated: emergence percentage, emergence speed index, mean time of emergence, seedling height, stem diameter, root length, shoot dry matter, root dry matter and total dry matter. The cultivar Orelha-de-Vó showed higher tolerance to saline stress in emergence percentage, mean time of emergence, stem diameter, root length, root dry matter and total dry matter in comparison to the other cultivars.

Keywords: Phaseolus lunatus L., salinity, tolerance

\section{INTRODUÇÃO}

O feijão-fava (Phaseolus lunatus L.) é uma leguminosa pertencente à família Fabaceae, conhecida popularmente como fava, feijão-de-lima, feijão-espadinho e tem como centro de origem para a forma cultivada da espécie a região central da Mesoamérica, e mais precisamente a Guatemala (SILVA et al., 2010). A sua produção é destinada principalmente ao autoconsumo das famílias que dispõem de uma importante fonte de proteína na dieta alimentar (BARBOSA; ARRIEL, 2018).

A cultura fava apresenta grande variabilidade no tamanho, cor e forma das sementes, variação esta que parece estar relacionada ao genótipo. Para Marcos Filho (2005), um genótipo que apresente maior capacidade em translocar e armazenar nutrientes na semente tem maior potencial germinativo sob condições adversas de estresses abióticos, como por exemplo, a salinidade. No entanto, é necessário concentrar pesquisas para definir os estádios críticos da planta a salinidade desde a germinação até a colheita (SOARES FILHO et al., 2016).

Para Dias et al. (2016), em condições de altos níveis de sais solúveis na solução do solo, o crescimento, a expansão da superfície foliar e o metabolismo do carbono primário de muitas culturas são afetados negativamente devido ao efeito osmótico, déficit hídrico, toxicidade de íons e desequilíbrio nutricional. Salienta-se que associado ao acúmulo total de sais no solo, o estresse osmótico reduz a disponibilidade de água para os vegetais e pode, em consequência, afetar a porcentagem de emergência e o estabelecimento inicial da plântula (FREIRE et al., 2018).

Almeida et al. (2012), trabalhando com genótipos de feijão-caupi sob estresse salino, concluíram que o aumento da salinidade da água de irrigação diminui a velocidade e porcentagem de emergência das plântulas, sendo este efeito significativamente dependente do genótipo. No entanto, Nascimento et al. (2017) verificaram que a germinação de sementes da cultivar Roxinha de feijão-fava (Phaseolus lunatusL.) é elevada quando submetidas ao estresse salino.

Diante do exposto, o objetivo do presente trabalho foi avaliar a tolerância à salinidade de quatro cultivares de fava na emergência e no crescimento de plântulas.

\section{MATERIAL E MÉTODOS}

O experimento foi conduzido, em dezembro de 2017, na Horta Didática Professor Luiz Antônio da Silva, pertencente à Universidade da Integração Internacional da Lusofonia Afro-Brasileira (UNILAB), no Campus da Liberdade, Redenção-CE. O clima da região é do tipo Aw', sendo caracterizado como tropical chuvoso, muito quente, com chuvas predominantes nas estações do verão e outono (KOPPEN, 1923). A região apresenta precipitação média anual de $1.086 \mathrm{~mm}$, 


\section{EMERGÊNCIA E CRESCIMENTO INICIAL EM PLÂNTULAS DE CULTIVARES DE FAVA IRRIGADA COM ÁGUAS SALINAS}

temperatura média do ar de $26{ }^{\circ} \mathrm{C}$ e a umidade relativa média do ar de $71,26 \%$.

O delineamento experimental foi inteiramente casualizado (DIC), em esquema fatorial $5 \times 4$, referentes aos valores de condutividade elétrica da água de irrigação CEa: 1,$0 ; 2,0 ; 3,0 ; 4,0$ e $5,0 \mathrm{dS} \mathrm{m} \mathrm{m}^{-1}$, versus quatro cultivares de fava (Branquinha - $\mathrm{C} 1$, Manteiguinha - C2, Espírito Santo - C3 e Orelha-de-Vó - C4), com quatro repetições de 25 sementes.

As quatro cultivares de fava foram semeadas em 10 bandejas de isopor com 128 células $\left(40 \mathrm{~cm}^{3}\right)$ cada. $O$ material utilizado como substrato foi obtido por meio da mistura de areia, arisco e esterco, na proporção 4:1:1, respectivamente. Foi colocada 1 semente por célula, numa profundidade de $2 \mathrm{~cm}$.

As águas de irrigação foram preparadas através da diluição de sais solúveis $(\mathrm{NaCl}$, $\mathrm{CaCl}_{2} \cdot 2 \mathrm{H}_{2} \mathrm{O}$ e $\mathrm{MgCl}_{2} \cdot 6 \mathrm{H}_{2} \mathrm{O}$ ) na proporção equivalente de 7:2:1 entre $\mathrm{Na}, \mathrm{Ca}$ e $\mathrm{Mg}$, em

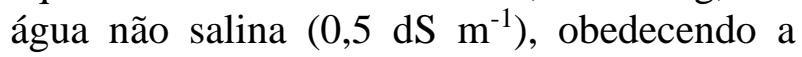
relação entre $\mathrm{CEa}$ e a sua concentração $\left(\mathrm{mmol}_{\mathrm{c}}\right.$ $\left.\mathrm{L}^{-1}=\mathrm{CE} \times 10\right)$, conforme metodologia proposta por Rhoades (2000). A irrigação foi aplicada manualmente em uma frequência diária.

A emergência foi monitorada diariamente, registrando-se o número de plântulas emergidas até 21 DAS, e as amostras para análise de biomassa, foram coletadas, separadas, identificadas e secas em estufa a 65 ${ }^{\circ} \mathrm{C}$ com circulação forçada de ar durante $72 \mathrm{~h}$. A biomassa foi determinada em gramas (g).

Para avaliar o efeito dos tratamentos, foram analisadas as seguintes variáveis: porcentagem de emergência (PE), determinada aos 21 DAS, através da contagem de plântulas normais em condições não salinas; índice de velocidade de emergência (IVE), onde foram realizadas contagens diárias das plântulas, adotando-se a metodologia recomendada por Maguire (1962) e tempo médio de emergência (TME), realizando-se contagens diárias das sementes, conforme metodologia proposta por Labouriau (1983), com o resultado expresso em dias.

Para avaliar o efeito da salinidade no crescimento inicial foram coletadas 4 plântulas por tratamento $\mathrm{e}$ analisadas as seguintes variáveis: altura de plântulas (AP) medida com fita métrica a partir do início do caule, diâmetro de caule (DC) mensurado com paquímetro digital na base do caule, comprimento da raiz $(\mathrm{CR})$ e as massas secas da parte aérea (MSPA), da raiz (MSR) e total (MST) das plântulas, que foram postas para secar em estufa a $65{ }^{\circ} \mathrm{C}$, até atingirem valor constante de matéria seca.

Os dados observados foram submetidos às análises de variância e regressão para condutividade elétrica da água e as médias foram comparadas pelo teste de Tukey, para as cultivares $(p<0.05)$, utilizando-se o software estatístico ASSISTAT versão 7.7 beta (SILVA; AZEVEDO, 2016). Na análise de regressão, as equações foram escolhidas com base na significância dos coeficientes de regressão a $1 \%(* *)$ e $5 \%(*)$ de probabilidade pelo teste $\mathrm{F}$ e no maior coeficiente de determinação $\left(\mathrm{R}^{2}\right)$.

\section{RESULTADOS E DISCUSSÃO}

Pela a análise de variância constatou-se interação significativa entre a salinidade e a cultivar para todas as variáveis estudadas (Tabela 1). Tais resultados permitem inferir que no estabelecimento das plântulas, as cultivares da fava apresentaram características genéticas relacionadas às sementes que podem tolerar o efeito tóxico e ao déficit hídrico causado pela salinidade.

Esse efeito pode estar relacionado ao comprimento e largura das sementes de fava que variam de 7,8 a 17,5 e a largura de 5,8 a $11,7 \mathrm{~mm}$, respectivamente (SANTOS et al., 2002). 
Tabela 1. Resumo da análise de variância para porcentagem de emergência (PE), índice de velocidade de emergência (IVE), tempo médio de emergência (TME), de 4 cultivares de fava cultivadas sob diferentes níveis de salinidade da água de irrigação.

\begin{tabular}{ccccc}
\hline \multirow{2}{*}{ FV } & \multirow{2}{*}{ GL } & \multicolumn{3}{c}{ Quadrado médio } \\
\cline { 3 - 5 } & & PE & IVE & TME \\
\hline Salinidade (S) & 4 & $2327,02^{* *}$ & $2,68^{* *}$ & $12,07^{* *}$ \\
Cultivar (C) & 3 & $1694,29^{* *}$ & $5,18^{* *}$ & $4,19^{* *}$ \\
S X C & 12 & $954,94^{* *}$ & $0,57^{* *}$ & $2,91^{* *}$ \\
Resíduo & 60 & 34,67 & 0,01 & 0,17 \\
CV\% & - & 8,04 & 7,33 & 4,71 \\
\hline
\end{tabular}

FV: fonte de variação, GL: grau de liberdade, CV: coeficiente de variação, ${ }^{* *}$ Significativo a $1 \%$, ${ }^{*}$ Significativo a 5\%, ${ }^{\text {ns }}$ não significativo $(\mathrm{p}>=0.05)$.

Quanto à porcentagem de emergência (Figura 1A), para as cultivares Branquinha e Orelha-de-vó o modelo que melhor se ajustou foi o linear. No entanto, para cultivar Manteiguinha e Espírito Santo, foi o polinomial quadrático com valor máximo de $77,19 \%$ e $94,2 \%$ da PE referentes a condutividade elétrica da água de irrigação de 2,08, e 2,89 $\mathrm{dS} \mathrm{m}^{-1}$, respectivamente.

Esse resultado pode estar relacionado à variação genética entre as cultivares e ao tamanho das sementes, conforme observado por Freire et al. (2018), em diferentes cultivares de arroz.
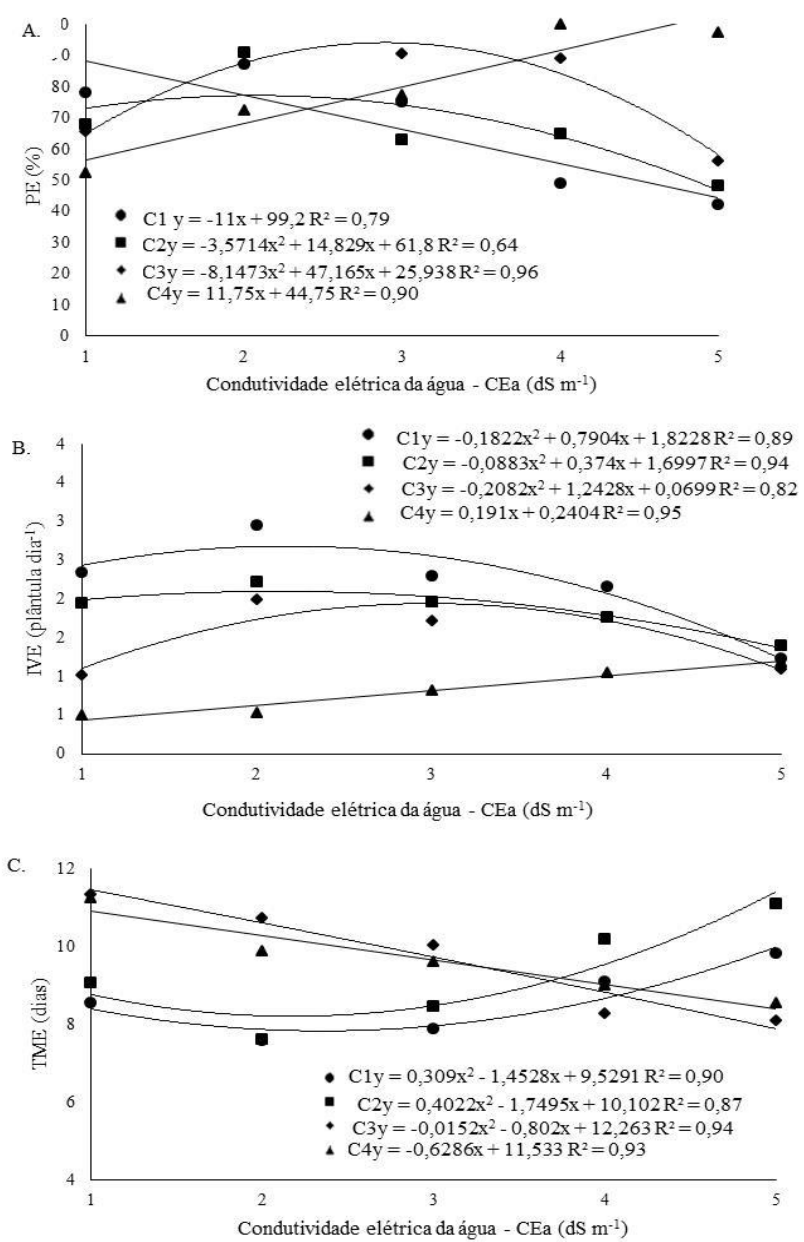

Figura 1. Porcentagem de emergência (A), índice de velocidade de emergência (B) e tempo médio de emergência (C) de cultivares de fava (C1 - Branquinha, C2 - Manteiguinha e C3 - Espirito santo e C4 - Orelha-de-Vó) submetida a diferentes níveis de salinidade. 


\section{EMERGÊNCIA E CRESCIMENTO INICIAL EM PLÂNTULAS DE CULTIVARES DE FAVA IRRIGADA COM ÁGUAS SALINAS}

As cultivares apresentaram uma redução de PE com aumento dos sais na água de irrigação, com exceção da cultivar Orelha-devó, mostrando-se ser a cultivar com maior desempenho sob condições de estresse salino ser a cultivar com melhores resultados. Ou seja, ela conseguiu absorver água suficiente para ativar o metabolismo e consequentemente o ajustamento osmótico, possibilitando a emergência das estruturas que condicionam uma plântula normal (CARVALHO; NAKAGWA, 2012).

A menor porcentagem de emergência pode estar relacionada com a diminuição da capacidade de embebição das sementes, ocasionado pela redução do potencial osmótico do substrato, ao excesso de sais disponíveis na água de irrigação (ALBUQUERQUE et al., 2016), além da possibilidade de ocasionar o rompimento das camadas tegumentares e causar danos ao embrião, podendo levar à morte das sementes (FREITAS et al., 2013).

Para o índice de velocidade de emergência (Figura 1B), observou-se ajustes quadráticos para as cultivares Branquinha, Manteiguinha e Espírito Santo, com valores máximos de 2,68 plântulas dia ${ }^{-1}$ para a CEa de 2,20 dS m $\mathrm{d}^{-1}$, de 2,10 plântulas dia ${ }^{-1}$ para a $\mathrm{CEa}$ de 2,08 dS m${ }^{-1}$ e de 1,93 plântulas dia $^{-1}$ para a CEa de 2,96 dS m $\mathrm{m}^{-1}$, respectivamente, e linear para Orelha-de-Vó. Essa redução gradual no percentual germinativo e nos valores de IVE também foi constatada por Larré et al. (2014) que ao avaliarem plântulas de arroz submetidas ao estresse salino, obtiveram resultados semelhantes.

Nascimento et al. (2017) ao avaliarem plântulas da cultivar Branca de feijão de fava em diferentes concentrações de $\mathrm{NaCl}$ na água de irrigação, obtiveram resultados similares. Freire et al. (2018) ao avaliarem cultivares de arroz submetidas ao estresse salino, também obtiveram redução no percentual germinativo e nos índices de velocidade de emergência das plântulas de arroz em concentração salinidade de $2 \mathrm{dS} \mathrm{m}^{-1}$.

Para o tempo médio de emergência, o modelo polinomial quadrático foi $\mathrm{o}$ que melhor se ajustou para as cultivares Branquinha e Manteiguinha (Figura 1C), sendo observado redução de 7, 83 e 8,20 dias, respectivamente, com o aumento da $\mathrm{CEa}$ em torno de 2,35 e 2,19 $\mathrm{dS} \mathrm{m}^{-1}$, demostrando maior tolerância aos sais, em comparação às cultivares Espírito Santo e Orelha-de-Vó, que apresentaram redução com as concentrações de sais na água de irrigação, seguindo um modelo linear decrescente.

$O$ atraso na emergência resulta da redução do potencial osmótico da solução do substrato, causada pelo aumento da concentração de sais solúveis, interferindo negativamente na disponibilidade de água no solo e, consequentemente, na absorção de água pelas sementes (SANTOS et al., 2011). Por outro lado, Coelho et al. (2017), verificaram que o aumento da concentração da solução salina $(50 \mathrm{mM}$ de $\mathrm{NaCl})$ levou a um crescimento no tempo médio de emergencia na cultura de arroz.

Conforme análise de variância (Tabela 2), houve efeito significativo da salinidade da água de irrigação $(\mathrm{p}<0,01)$ para todas as variáveis de crescimento, evidenciando comportamento distinto entre os cultivares em relação as variáveis avaliadas com as concentrações de sais na água de irrigação, explicado pelo genótipo de cada cultivar ao estresse salino. 
Tabela 2. Resumo da análise de variância para altura de plântula (AP), diâmetro de caule (DC), comprimento da raiz (CR), massa seca da parte aérea (MSPA), massa seca da raiz (MSR) e massa seca total (MST) de quatro cultivares de fava cultivadas sob diferentes níveis de salinidade da água de irrigação.

\begin{tabular}{|c|c|c|c|c|c|c|c|}
\hline \multirow[b]{2}{*}{ FV } & \multirow[b]{2}{*}{ GL } & \multicolumn{5}{|c|}{ Quadrado médio } & \multirow[b]{2}{*}{ MST } \\
\hline & & $\mathrm{AP}$ & DC & $\mathrm{CR}$ & MSPA & MSR & \\
\hline $\begin{array}{c}\text { Salinidade } \\
\text { (S) }\end{array}$ & 4 & $118,21^{\mathrm{ns}}$ & $1,22^{\mathrm{ns}}$ & $20,69^{\text {ns }}$ & $0,021^{\mathrm{ns}}$ & $0,061^{* *}$ & $0,073^{* *}$ \\
\hline Cultivar (C) & 3 & $114,89^{* *}$ & $1,14^{* *}$ & $2,84^{*}$ & $0,042^{* *}$ & $0,193^{* *}$ & $0,367^{* *}$ \\
\hline $\mathrm{S} \times \mathrm{C}$ & 12 & $23,78^{* *}$ & $0,11^{*}$ & $2,61^{* *}$ & $0,016^{* *}$ & $0,050^{* *}$ & $0,071^{* *}$ \\
\hline Resíduo & 60 & 2,38 & 0,05 & 0,84 & 0,004 & 0,009 & 0,015 \\
\hline $\mathrm{CV} \%$ & - & 8,44 & 6,66 & 12,22 & 17,22 & 25,05 & 16,35 \\
\hline
\end{tabular}

FV: fonte de variação, GL: grau de liberdade, CV: coeficiente de variação, ${ }^{* *}$ Significativo a $1 \%,{ }^{*}$ Significativo a $5 \%,{ }^{\text {ns }}$ não significativo $(\mathrm{p}>=0.05)$.

A altura de plântula foi reduzida à medida que se aumentou o nível salino da água da irrigação (Figura 2A). A equação que melhor representou a resposta das plântulas foi do tipo polinomial quadrática com pontos máximos de 20,29 $\mathrm{cm}$ na CEa de 2,09 $\mathrm{dS} \mathrm{m}^{-1}$ para Branquinha, 22,04 $\mathrm{cm}$ na CEa de 2,16 dS $\mathrm{m}^{-1}$ para Manteiguinha, 20,79 $\mathrm{cm}$ na CEa de $2,66 \mathrm{dS} \mathrm{m}^{-1}$ para Espírito Santo e $16,16 \mathrm{~cm}$ na CEa de 2,63 dS $\mathrm{m}^{-1}$ para Orelha-de-Vó. Redução do parâmetro de altura de plântulas em resposta à salinidade também foram observados por Oliveira et al. (2013) em feijão-caupi.

Essa resposta ressalta os efeitos do estresse salino sobre as plântulas de fava que afeta o crescimento quando irrigado com água salinas superiores a $2 \mathrm{dS} \mathrm{m}^{-1}$ devido aos efeitos de toxicidade proporcionado pelas altas concentrações de sódio na agua de irrigação, que além de promover efeitos tóxicos devido a íons específicos também exerce efeito de origem nutricional (SYVERTSEN; GARCIASANCHEZ, 2014).

O diâmetro de plântula foi reduzido linearmente com o aumento da salinidade da água de irrigação (Figura 2B), no entanto, a cultivar Orelha-de-Vó foi a menos afetada pelas condições salinas, de forma que a redução só foi expressiva a partir da salinidade de $3 \mathrm{dS} \mathrm{m}^{-1}$.

Prazeres et al. (2015) constataram redução do diâmetro em feijão-caupi a partir da concentração salina estimada em 1,55 e 2,1 $\mathrm{dS} \mathrm{m}^{-1}$, respectivamente. Contrariando esse resultado, Almeida et al. (2012) encontraram, resultados diferentes no diâmetro de plântula do feijão-caupi. 

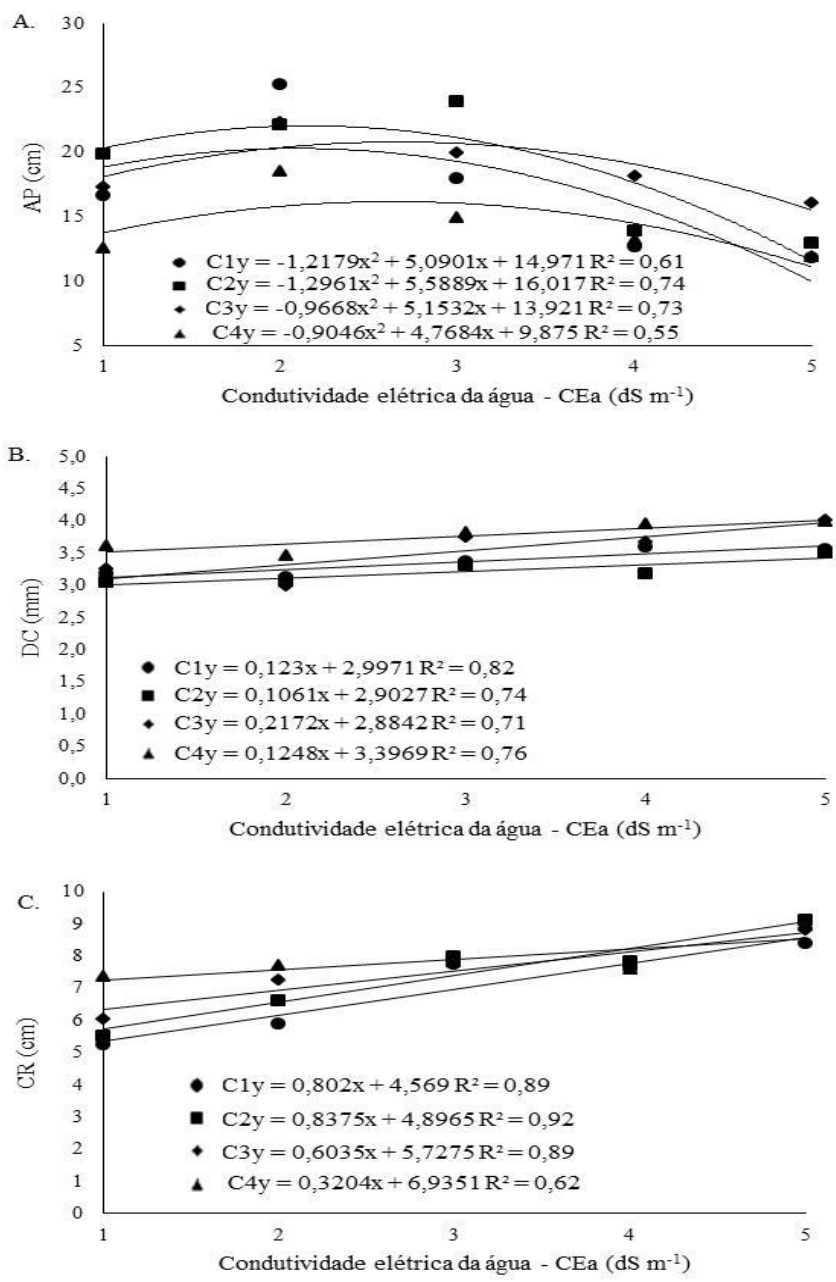

Figura 2. Altura de plântula (A), diâmetro de caule (B) e comprimento da raiz (C) de cultivares de fava (C1 Branquinha, C2 - Manteiguinha e C3 - Espírito Santo e C4 - Orelha-de-Vó) submetidas a diferentes níveis de salinidade.

O estresse salino afetou o comprimento da raiz para todas cultivares respectivamente (Figura 2C). Estudos conduzidos por Dalchiavon et al. (2016), utilizando sementes de feijão-comum sob estrese salino, também indicaram que o aumento da concentração salina ocasionou redução no crescimento da raiz de feijão. Guimarães et al. (2013), reforçam que o efeito da salinidade sobre o desenvolvimento radicular se deve, em parte, ao fato das raízes ficarem em contato direto com os sais do meio.

O aumento da condutividade elétrica da água reduziu a massa seca da parte aérea das cultivares Branquinha e Manteiguinha, observando assim efeito linear decrescente em função do aumento da salinidade da água de irrigação

(Figura 

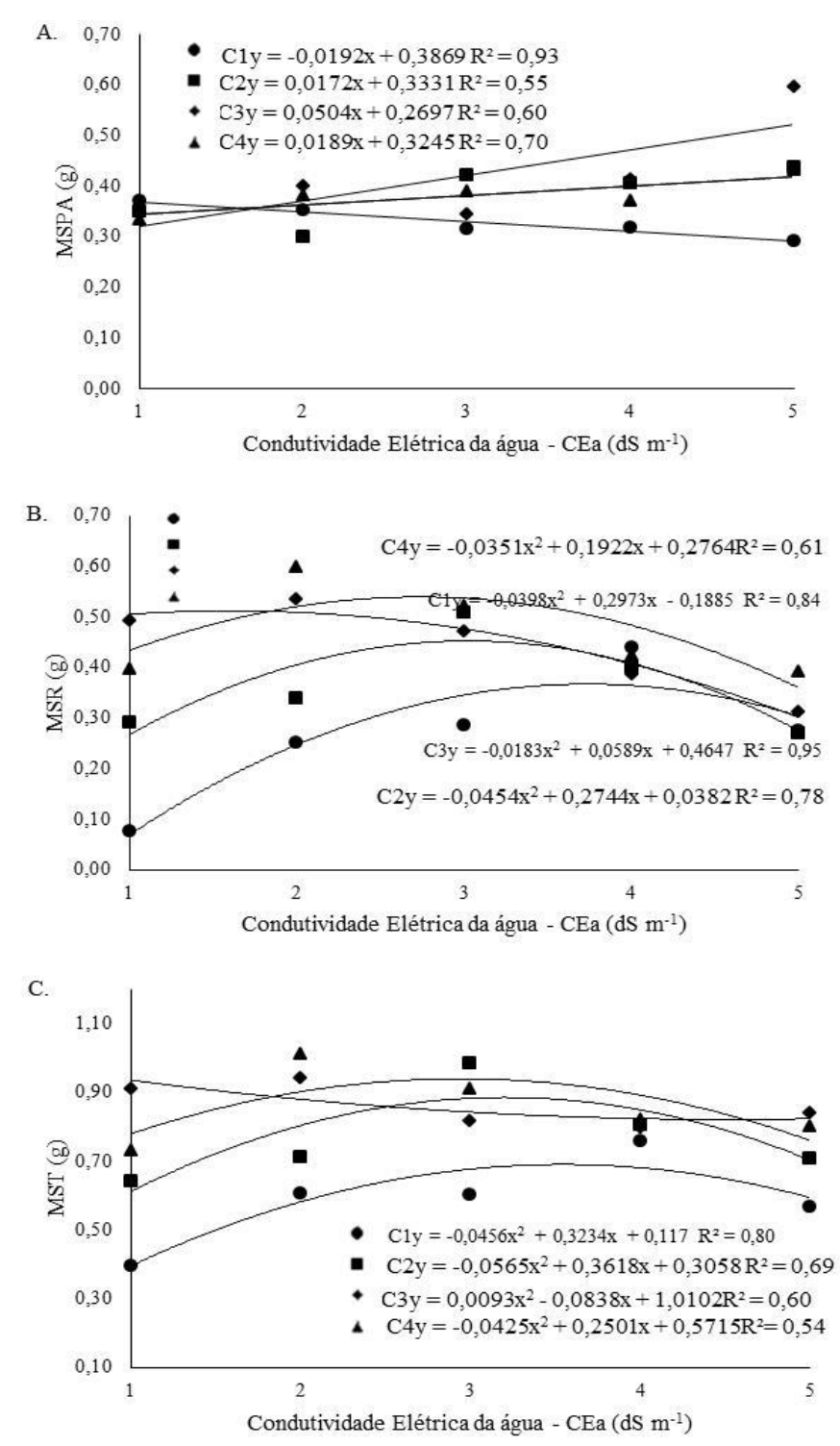

Figura 3. Massa seca da parte aérea (A), massa seca da raiz (B) e massa seca total (C) de cultivares de fava (C1 Branquinha, C2 - Manteiguinha e C3 - Espírito santo e C4 - Orelha-de-Vó) submetidas a diferentes níveis de salinidade.

A redução do acúmulo de fitomassa na parte aérea em função do aumento da salinidade indica ineficiência do processo fotossintético, de modo que os produtos oriundos da fotossíntese não são suficientes para suprir as necessidades dos órgãos das plantas, e ao mesmo tempo promover o crescimento destes (OLIVEIRA et al., 2015).

Observa-se ainda, que as cultivares Espírito Santo e Orelha-de-Vó apresentaram comportamento diferenciado das demais cultivares, pois com aumento da condutividade elétrica da água houve incremento da massa seca da parte aérea. Esse resultado estar relacionado ao fato de que as cultivares Espírito Santo e Orelha-de-Vó terem sido capazes de desenvolver um ajustamento osmótico superior ao das outras cultivares, colaborando, assim, para a manutenção da absorção de água e turgescência celular, garantindo a ocorrência de processos fisiológicos vitais como a expansão celular, e possibilitando, maior produção de massa seca (DUTRA el al., 2017).

Para a massa seca da raiz, constatou-se modelo quadrático, com pontos máximos de $0,37 \mathrm{~g}$ na $\mathrm{CEa}$ de $3,73 \mathrm{dS} \mathrm{m}^{-1}$ para Branquinha, 0,46 g na CEa de 3,05 $\mathrm{dS} \mathrm{m}^{-1}$ para Manteiguinha, 0,51 g na CEa de 1,47 dS 
$\mathrm{m}^{-1}$ para Espírito Santo e 0,54 g na CEa de $2,75 \mathrm{dS} \mathrm{m}^{-1}$ para a cultivar Orelha-de-Vó (Figura 3B). Corroborando essa informação, Oliveira et al. (2015), em plântulas de beterraba, também registraram uma redução da MSPA quando aplicaram concentrações crescentes de sais na água de irrigação. Para os autores a redução está relacionada à alta concentração de íons sódio no solo, promovendo alterações iônicas e tóxicas sobre o eixo embrionário, inibindo com isso $\mathrm{o}$ crescimento radicular.

O aumento da condutividade elétrica da água reduziu a massa seca total das cultivares de fava, observando-se assim modelo quadrático em função do aumento da salinidade da água de irrigação (Figura 3C) com valores máximos de $0,70 \mathrm{~g}$ na $\mathrm{CEa}$ de 3,60 dS m $\mathrm{m}^{-1}, 0,89 \mathrm{~g}$ na CEa de 3,20 $\mathrm{dS} \mathrm{m}^{-1}$, $0,82 \mathrm{~g}$ na CEa de $4,19 \mathrm{dS} \mathrm{m}^{-1}$ e $0,94 \mathrm{~g}$ na CEa de 2,94 $\mathrm{dS} \mathrm{m}^{-1}$ para as cultivares Branquinha, Manteiguinha, Espírito Santo e Orelha-de-Vó, respectivamente.

Os resultados podem ser explicados por Willadino et al. (2011) ao constatarem que a inibição no crescimento e produção de fitomassa pelas plantas em geral, é resposta do desequilíbrio nutricional e toxicidade, que resultam em perdas de respiração, expansão radicular, absorção de água e fixação de $\mathrm{CO}_{2}$.

\section{CONCLUSÕES}

A cultivar Espirito Santo possui maior tolerância ao estresse salino quanto à massa seca da parte aérea.

A cultivar Orelha-de-Vó apresenta maior tolerância ao estresse salino na porcentagem de emergência, tempo médio de emergência, diâmetro de caule, comprimento de raiz, massa seca da raiz e massa seca total em relação às demais cultivares.

\section{AGRADECIMENTOS}

Ao Conselho Nacional de Desenvolvimento Científico e Tecnológico
(CNPq) pelo suporte financeiro para a realização dessa pesquisa e à Fundação Cearense de Apoio ao Desenvolvimento Científico e Tecnológico (Funcap) pela concessão da bolsa de estudo.

\section{REFERÊNCIAS BIBLIOGRÁFICAS}

ALBUQUERQUE, J. R. T; SÁ, F. V. S.; OLIVEIRA, F. A.; PAIVA, E. P., ARAÚJO, E. B. G. A., SOUTO, L.S. Crescimento inicial e tolerância de cultivares de pepino sob estresse salino. Revista Brasileira de Agricultura Irrigada, v. 10, n. 2, p. 486 495, 2016. DOI: 10.7127/rbai.v10n200355.

ALMEIDA, W. S.; FERNANDES, F. R. B.; BERTINI, C. H. C. M.; PINHEIRO, M. S.; TEÓFILO, E. M. Emergência e vigor de plântulas de genótipos de feijão-caupi sob estresse salino. Revista Brasileira de Engenharia Agrícola e Ambiental, v. 16, n. 10, 2012. http://dx.doi.org/10.1590/S141543662012001000003.

BARBOSA, G. J.; ARRIEL, N. H. C. Feijãofava e a agricultura familiar de serraria, PB. Cadernos de Ciência \& Tecnologia. v. 35, n. 3, p. 387-403, 2018. http://dx.doi.org/10.35977/01041096.cct2018.v35.26393.

CARVALHO, N. M.; NAKAGAWA, J. Sementes: ciência, tecnologia e produção. 5 ed. Jaboticabal: FUNEP, 2012, 590p.

COELHO, D. S.; SILVA, J. A. B.; NASCIMENTO, R. L.; COSTA, J. D. S; SEABRA, T. X. Germinação e crescimento inicial de variedades de feijão caupi submetidas a diferentes concentrações salinas.

Revista Verde de Agroecologia e Desenvolvimento Sustentável, v. 12, n.2, p.261-266, 2017. https://doi.org/10.18378/rvads.v12i2.4419.

DALCHIAVON, F. C.; NEVES, G.; HAGA, K. I. Efeito de stresse salino em sementes de 
Phaseolus vulgaris. Revista de Ciências Agrárias, v.39, n.3, p.404-412, 2016. http://dx.doi.org/10.19084/RCA15161.

DIAS, N. S.; BLANCO, F. F.; SOUZA, E. R.; FERREIRA, J. F. S.; NETO, O. N. SOUSA.; QUEIROZ, I. S. R. Efeitos dos sais na planta e tolerância das culturas à salinidade. In: GHEYI, H. R.; DIAS, N.S.; LACERDA, C.F. DE; GOMES FILHO. Manejo da salinidade na agricultura: Estudos básicos e aplicados. Fortaleza, INCTSal, 2016. p. 151-161.

FREITAS, A. R.; LOPES, J. C.; MATHEUS, M. T.; MENGARDA, L. H. G.; CALDEIRA, M. V. W. Superação da dormência de sementes de jatobá. Pesquisa Florestal Brasileira, v. 33, n. 73, p. 85-90, 2013. https://doi.org/10.4336/2013.pfb.33.73.350.

FREIRE, M. H. D. C.; SOUSA, G. G.; SOUZA, M. V.; CEITA, E. D. A. R.; FIUSA, J. N.; LEITE, K. N. Emergence and biomass accumulation in seedlings of rice cultivars irrigated with saline water. Revista Brasileira de Engenharia Agrícola e Ambiental, v.22, n.7, p.471-475, 2018. http://dx.doi.org/10.1590/18071929/agriambi.v22n7p471-475.

GUIMARÃES, I. P.; OLIVEIRA, F.N.; VIEIRA, F. E. R.; TORRES, S. B. Efeito da salinidade da água de irrigação na emergência e crescimento inicial de plântulas de mulungu. Revista Brasileira de Ciências Agrárias, v.8, p.137-142, 2013. http://dx.doi.org/10.5039/agraria.v8i1a2360.

\section{KOPPEN, W. Dieklimate dererde-grundrib} der kimakunde. Berlin, Walter de gruyter verlag, 1923.

LABOURIAU, L. G. A germinação das sementes. Washington: Secretaria Geral da Organização dos Estados Americanos, 1983, $174 \mathrm{p}$.

LARRÉ, C. F.; MARINI, P.; MORAES, C. L.; AMARANTE, L.; MORAES, D. M. Influência do 24-epibrassinolídeo na tolerância ao estresse salino em plântulas de arroz. Semina: Ciências Agrárias, v. 35, n. 1, p. 6776, 2014.

MAGUIRE, J. D. Speed of germination-aid in selection and evaluation for seedling emergence and vigor. Crop Science, v. 2, n. 2, p. 176-177, 1962. http://dx.doi.org/10.2135/cropsci1962.001118 3X000200020033x.

MARCOS FILHO, J. Fisiologia de sementes de plantas cultivadas. Piracicaba: FEALQ, 2005, 495p.

NASCIMENTO, M. G. R.; ALVES, E. U.; SILVA, M. S.; RODRIQUES, C. M. Sementes de Phaseolus lunatus L. Submetidas a concentrações salinas e diferentes temperaturas. Rer. Caatinga, v.30, n.3, p.738747, 2017.

OLIVEIRA, F. A.; MEDEIROS, J. F.; OLIVEIRA, M. K. T.; SOUZA, A. A. T.; FERREIRA, J. A.; SOUZA, M. S. Interação entre salinidade e bioestimulante na cultura do feijão caupi. Revista Brasileira de Engenharia Agrícola e Ambiental, v. 17, n. 5, p. 465-471, 2013. http://dx.doi.org/10.1590/S141543662013000500001.

OLIVEIRA, F. A.; SÁ, F. V. S.; PAIVA, E. P.; ARAÚJO, E. B. G.; SOUTO, L. S.; ANDRADE, R. A.; SILVA, M. K. N. Emergência e crescimento inicial de plântulas de beterraba cv. Chata do Egito sob estresse salino. Agropecuária Científica no Semiárido, v.11, n.1, p.01-06, 2015.

PRAZERES, S. S.; LACERDA, C. F.; BARBOSA, F. E. L.; AMORIM, A. V.; ARAUJO, I. C. S.; CAVALCANTE, L. F. Crescimento e trocas gasosas de plantas de feijão-caupi sob irrigação salina e does de potássio. Revista Agro@mbiente, v.9, n.2, p. 111 - 118, $2015 . \quad$ http://dx.doi.org/10.18227/19828470ragro.v9i2.2161. 
RHOADES, J. P.; KANDIAH, A.; MASHALI, A. M. Uso de águas salinas para a produção agrícola. Estudos FAO 48, Campina Grande: UFPB, 2000. 117p.

SANTOS, D.; CORLETT, F. M. F.; MENDES, J. E. M. F.; WANDERLEY JÚNIOR, J. S. A. Produtividade e morfologia de vagens e sementes de variedades de fava no Estado da Paraíba. Pesquisa Agropecuária Brasileira, v.37, n.10, p.1407-1412, 2002.

SANTOS, K. C. F.; SILVA, M. S. L.; SILVA, L. E.; MIRANDA, A. M.; FREIRE, M. B. G. S. Atividade biológica em solo salino sódico saturado por água sob cultivo de Atriplex nummularia. Revista Ciência Agronômica, v.42, n.3, p.619-627, 2011.

SILVA, K. J. D. e; LOPES, A. C. de A.; GOMES, R. L. F.; SOUSA, F. M. de; ROCHA, M. de M. Recursos Genéticos. In: LOPES, A.C. de A.; GOMES, R.L.F.; ARAÚJO, A.S.F. de (Ed.). A cultura do feijão-fava no Meio-Norte do Brasil. Teresina: Ed. Universidade Federal do Piauí, 2010b. p.9-44.

SILVA, F. A. S. E.; AZEVEDO, C. A. V. The Assistat Software Version 7.7 and its use in the analysis of experimental data. African Journal of Agricultural Research. v.11(39), p.3733-3740, 2016. https://doi.org/10.5897/AJAR2016.11522.
SOARES FILHO, W. S.; GHEYI, H. R.; BRITO, M. E. B.; NOBRE, R. G.; FERNANDES, P. D.; MIRANDA, R. S. MELHORAMENTO GENÉTICO E SELEÇÃO DE CULTIVARES TOLERANTES À SALINIDADE. IN: GHEYI, H. R.; DIAS, N. S.; LACERDA, C. F.; GOMES FILHO, E. Manejo da salinidade na agricultura: Estudo básicos e aplicados. 2.ed. Fortaleza: INCTSal, Cap.17, 2016. p.259-274.

SYVERTSEN, J. P.; GARCIA-SANCHEZ, F. Multiple abiotic stresses occurring with salinity stress in citrus. Environmental and Experimental Botany, v.103, n.6, p.128-137, 2014.

https://doi.org/10.1016/j.envexpbot.2013.09.0 15.

TAIZ, L.; ZEIGER, E. Fisiologia vegetal. 5. ed. Porto Alegre: Artmed, 2013. 918p.

WILLADINO, L.; GOMES, E. W. F.; SILVA, E. F. F.; MARTINS, L. S. S.; CAMARA, T. R. Efeito do estresse salino em genótipos tetraplóides de bananeira. Revista Brasileira de Engenharia Agrícola e Ambiental, v. 15, n. 1 p.53-59, 2011. http://dx.doi.org/10.1590/S141543662011000100008 . 